\title{
Tesis de pregrado, Facultad de Estomatología, 2002.
}

En el presente estudio se evaluó el efecto de la modificación del patrón de lateral y la inhibición propioceptiva en sujetos con función de grupo total. Se observaron 5 sujetos con función de grupo como patrón de lateralidad bilateral a los que se le registraron la actividad electromiográfica (AEMG) de los músculos Masetero, fascículo anterior del Temporal y vientre anterior del Digástrico en posiciones de reposo, apretamiento máximo en oclusión habitual y en lateralidad derecha, además de masticación unilateral derecha con alimento blando y duro. Los registros fue-

Se analizaron 130 casos de tumores de glándulas salivales (GS) de la Unidad de Patología Oral de la Facultad de Estomatología de la Universidad Peruana Cayetano Heredia, con el objetivo de establecer la frecuencia de presentación por edad, género y localización. Correspondieron a GS mayores (GSM) $53(40.77 \%)$ casos y $77(59.23 \%)$ a GS menores (GSm); 82(63.08\%) fueron benignos, afectando $36(43.9 \%)$ a GSM y $46(53.10 \%)$ a GSm; $48(36.92 \%)$ fueron malignos, distribuyéndose 17(35.53\%)

Durante el año 2002 se sustentaron 53 tesis de pregrado, todas se encuentran a disposición de los interesados en la Biblioteca Central de la UPCH. Dentro de ellas recibieron el calificativo de sobresaliente tres tesis cuyos resúmenes se publican a continuación.

\section{Evaluación del efecto del cambio del patrón de lateralidad de fun- ción en grupo a guía canina y la inhibición de la propiocepción periodontal del canino y piezas posteriores en la actividad de los músculos maseteros, fascículo anterior del temporal y vientre an- terior del digastrico en sujetos con normoclusión de 16 a 21 años de edad.}

Berastain Arenas, Juan Francisco

ron tomados el mismo día en cuatro condiciones para cada sujeto: 1)Función en Grupo (FG), 2) Guía Canina Artificial (GCAr), 3) Función en Grupo con inhibición propioceptiva del canino y piezas posteriores (Fga) y 4) Guía Canina Artificial con inhibición del canino (GCAra). Los resultados fueron analizados mediante ANOVA. No se evidencia diferencias significativas en reposo y apretamiento máximo en oclusión habitual. En las otras posiciones evaluadas se apreciaron diferencias significativas al cambiar el patrón de lateralidad e inhibir la propiocepción periodontal.
La disminución de contactos posteriores o la presencia de contacto exclusivo del canino reducirá la actividad muscular masticatoria principalmente en el lado de trabajo. La inhibición de la propiocepción producirá un efecto distinto de acuerdo a la posición. En posiciones parafuncionales la propiocepción canina y posterior controla la contracción del Temporal y en posición funcional la propiocepción del canino controla al Digástrico y la del canino y piezas posteriores activan al Masetero y Digástrico.

Frecuencia de tumores epiteliales de glándulas salivales por edad, genero y localización, registradas en la Unidad de Patología Oral de la Facultad de Estomatología de la Universidad Peruana Cayetano Heredia.

Delgado Bravo, Miguel Sebastián

en GSM y $31(64.58 \%)$ en GSm. La edad promedio para los T. Benignos fue 40.93 años y para los malignos 48.19 años. La localización más frecuente fue el paladar seguido de la parótida. En GSM la parótida ocupó el primer lugar para T. Benignos y la submaxilar para malignos, en GSm el paladar duro fue la zona de mayor localización para los dos tipos de tumores. Los T. Benignos diagnosticados fueron: Adenoma pleomórfico (44.62\%), Cistadenoma (7.69\%), Mioepitelioma $(8.46 \%)$ y Adenoma de células basales $(2.31 \%)$. Los T. Malignos diagnosticados fueron: Carcinoma adenoideo quístico (16.15\%), Adenocarcinoma no especificado de otra manera (9.23\%), Carcinoma mucoepidermoide

$(6.15 \%)$, Adenocarcinoma de células acinares $(3.08 \%)$, Adenocarcinoma de células claras (1.54\%) y Adenocarcinoma polimorfo de bajo grado $(0.77 \%)$. El mayor número de tumores se presentó en el género femenino. 


\section{Análisis de los factores mas importantes para el diagnostico de problemas articulares dentro de los desordenes -temporoman- dibulares en sujetos de 15 a 20 años de edad.}

Ohashi Yusa, Elizabeth

Numerosos signos y síntomas han sido descritos en la literatura para el diagnóstico de Desórdenes Temporomandibulares (DTM). El presente estudio trata de analizar y seleccionar cuales de estos factores están directamente relacionados con el diagnóstico articular de los DTM en adultos jóvenes. Ochenta y cinco sujetos entre los 15 y 20 años de edad fueron examinados utilizando el índice craneomandibular de Fricton. Los siguientes componentes relacionados con los criterios de diagnóstico de disfunción articular fueron analizados: movimiento mandibular, ruido articular y palpación articular. Análisis de correlación de Pearson y análisis factorial fueron utilizados para la simplificación de los criterios. Cuatro fueron los principales factores hallados: Factor 1 compuesto por dolor a la laterotrusión, limitación al movimiento y dolor a la palpación de la cápsula articular superior, posterior y lateral. Fac- tor 2 desviación lateral, rigidez mandibular, chasquido bilateral reproducible en apertura y cierre, y crepitación bilateral fina. Factor 3 chasquido bilateral recíproco y chasquido bilateral reproducible en lateralidad. Factor 4 crepitación bilateral gruesa. El presente estudio recomienda la utilización de estos cuatro factores para el diagnóstico y evaluación de desórdenes articulares. 